\title{
On the Collective Moods of Booms and Busts: Socio-Psychological Foundations in External Shock Communication and Social Volatility in the COVID-19 Economic Fallout
}

\author{
Julia M. Puaschunder ${ }^{1,2}$ \\ ${ }^{1}$ The New School, Parsons School of Design, Department of Economics, 6 East $16^{\text {th }}$ Street, $9^{\text {rd }}$ floor 89, New York, \\ NY 10003, USA, Julia.Puaschunder@newschool.edu, T 001212229 5700,F 0012122295724, \\ www.juliampuaschunder.com \\ ${ }^{2}$ Columbia University, Graduate School of Arts and Sciences, Julia.Puaschunder@columbia.edu, \\ http://blogs.cuit.columbia.edu/jmp2265
}

\begin{abstract}
The currently ongoing novel Coronavirus-crisis is an external shock coming down on society with direct impact on societal moods and subsequently connected economic changes. With growing digitalization and quickening of transfer speed, information exchange in the individual involvement to break trends online on a global scale may impose unknown systemic risks in causing social volatility in international economics. Research may explore how human beings' communication and interaction results in socially constructed volatility that echoes in economic correlates. This paper proposes to explore the role of communication and temporal foci in pandemic communication to create social volatility underlying economic downturns with attention to international differences. Comparing the economic consequence of the endogenous crunch of the 2008 World Financial Recession with the external economic shock of the COVID-19 pandemic could aid to retrieve crisis-specific recovery recommendations. Understanding how the social compound forms economic outcomes promises to explain how market outcomes are developed in society and can be shaped by strategic communication with special attention to new media technologies.
\end{abstract}

KEYWORDS: Collective moods, Communication, Coronavirus, COVID-19, Digitalization, Economic fundamentals, External shock, Information, Lockdown, News, Pandemic, Social volatility, SocioEconomics, Socio-Psychological Foundations, 2008/09 World Financial Crisis

\section{Introduction}

Globalization led to an intricate set of interactions between individuals, organizations and states (Centeno et al. 2013). Unprecedented global interaction possibilities have made communication more complex than ever before as the whole has different properties than the sum of its increasing diversified, global and instantly offered information parts. In the recent decade, data transfer and exchange online to create news increased qualitatively and quantitatively (Puaschunder 2017b, c). The reaping of surplus value from big data analyses and targeted online advertisement skyrocketed (Puaschunder 2017a, d). With growing digitalization and quickening of transfer speed, information exchange in the individual involvement to break trends online on a global scale may impose unknown systemic risks in causing social volatility in international economics (Puaschunder 2019).

In a socially-distanced COVID-19 world, we have become virtually closer and digitally more connected than ever before. But today's digital collective interaction effects may at the same time lead to hard-to-foreseeable fallacy of composition downfalls. Emergent risks in emotional reactions to information and collective moods triggered by online media news races appear to imbue social volatility into global economic systems (Centeno et al. 2013). The indexal flow of time created in constant instant communication online now is faster than ever before due to constantly overlapping contents and that are formed truly global. Online communication also appears to feature less accuracy checks than previous media forms. Governments seem to have lost their privilege of censorship control, which adds complexity and vulnerability to the building 
of a collective soul of booms and busts in the digital age (Puaschunder forthcoming). In all these features of the nature of online communication, new technology advancements may hold public reactions that may underlie the upswing or downturn of crisis dynamics.

In the light of growing data transfer and internet connectivity globalization, the demand for an in-depth understanding of how information echoes in socio-economic correlates gained unprecedented momentum. Social psychology may aid in explaining how social pressures materialize in economic fallouts. The proposed paper will draw on socio-psychological foundations to explain the collective reaction to the current technical communication about economic dynamics. Media information may cause collective moods fueled by redundant and self-reinforcing processes that lack control or censorship in the digital space. Collective moods in particular anxiety, fear and Angst but also euphoria and hysteresis - may play fundamental roles in consumer-spending and investment decisions. Forward-looking as one is always thinking ahead of oneself or ruminating in fear over the past may shape our economics of choice.

While we have information on the economic fundamentals and physical environment's impact on choices, the role of media information shaping people's economic outlook is missing. Media-driven information races may steer emotions and collective moods that cause systemic behavioral interpretation of an uncertain future that may lead to delayed consumption and spending decisions of individuals, households and firms further exacerbating in collective governmental investment and spending preferences. All these socio-economic impacts of affects and mass communication potentially underlying economic cycles, however, have hardly been described or empirically validated before.

In seeking to shed light on communication causing implicit system failures but also the potential socio-economic consequences of cumulative moods triggering mass movements that cause economic turmoil; the proposed research strives to uncover unexpected dangers and insufficiently described shadows of the invisible hand. The project will focus on behavioralsocial psychology aspects of financial crises and economic meltdowns. Most timely capturing the currently ongoing novel Coronavirus pandemic's contemporary Zeitgeist, the project will also address digital technologies' role in the representation and transmission of information creating social volatility. In explaining how communication during times of crises shapes economic fallouts, information transfer's unique impetus in the digital age will be unraveled in order to elucidate how strategic communication can serve as a novel and easily-implementable nudging economic stabilizer.

\section{Theory}

The theoretical part makes the case of a narrow technical focus on economic fundamentals and mathematical formalizations in classic economic to explain the mechanisms causing economic cycles missing out on the socio-psychological and behavioral group aspects of collective over- and underreaction in markets. While some information on euphoria is found in the animal spirits and behavioral finance literature describing overconfidence in markets leading to an overvaluation of assets, overleveraging and underestimation of risk; hardly any empirical studies explain collective panics from a socio-economic or social psychology angle.

The 2008/09 World Financial Recession offered some data on the collective souls of economic crunches, yet the crisis emerged as inherent feature in capitalism with the banking sector downfalls becoming the endogenous crunch factor. But how external influences can come down on society and materialize in an exogenous shock with drastic fallouts in the real economy due to new media coverage, we hardly have any economic model or empirical validation for. No data existed prior to COVID-19 that was so rich in terms of instant communication, global interconnectivity and computational power to make sense of unprecedentedly big data capacity generated instantaneously and globally. At the same time, the constant informational bombardment of multi-faceted new media tools requires to conserve the fluidly growing 'now'- 
driven information overload immediately (Center for Disease Control and Prevention 2020; International Monetary Fund 2020; Sachs et al. 2020; United Nations 2020a, b).

The proposed project aims at innovatively painting a novel picture of the mass psychological underpinnings of business cycles based on information flows with particular attention to digital communication. Addressing problems of the neoclassical assumption of perfect information markets through the lens of real competition, the proposed paper will specifically unravel how contemporary media communication produces certain types of expectations that form collective moods and how these change consumption patterns result in systemic global economic outcomes. After a thorough literature review on financial market theory with special attention to heterodox viewpoints, the history of economic cycles theories will lead to the analysis of the role of information in creating economic booms and busts. The concept of social volatility will be introduced and depicted in light of COVID-19. Social volatility adds to quantitative volatility any social aspects that influence and shape economic markets offering an innovative way to explain how and what information represented in the media creates economic ups and downs.

Attention will be paid to the concept of time and how temporal prospects elicited in mass media shape individual decision-making. Contrary to standard neoclassical ideas of time in discounting, a behavioral economic approach will be applied dividing time in past, present and future prospects. Present as the moment of 'now' attention will be captured to be highly fluid as for constantly being melted into the past by its future dependent on the past. This fungibility of dependent moments add temporal volatility. The highly fickle 'now' present moment unmasked as a slippery reference point will be addressed in the theory of subjectivity and reflected upon behavioral economics' hyperbolic discounting present bias. Media fetishizing breaking news waves of concurrently presented similar information missing out on diversification potential but also the crucial role of the media in perpetuating human present biases will be thematized. The media's untapped potential in setting potentially favorable or unfavorable anchors and building unknown economic choice architectures will be introduced.

As for social volatility, fat tail phenomena and robustness literature will be coupled by social systems' ideas. Affect Theory, Believes and Desires Theory will become the theoretical backbone to describe fallible likelihood estimations when the pains and joys over markets are felt collectively and social volatility waves break. How integrating indexicality, modality and subjectivity is related to intentionality will be explored. Reference point dependence on age and the 'now' will be investigated in light of Prospect theory to see how losses and gains represented in the past or future may lead to biased decision-making patterns. The present bias potentially overinflating social volatility risks based on emotionality will be thematized.

\section{Empirics}

Empirically, the current COVID-19 pandemic serves as an external shock coming down on society with direct impact on societal moods and subsequently connected economic changes (Puaschunder \& Beerbaum 2020; Puaschunder, Gelter \& Sharma 2020). Four studies will explore the role of communication and temporal foci in news (Study 1) to create social volatility underlying economic downturns (Study 2) with attention to international differences (Study 3). The economic consequence of the endogenous crunch of the 2008 World Financial Recession will be compared to the external economic shock of the COVID-19 pandemic in order to retrieve crisis-specific recovery recommendations (Study 4).

Study 1: Exploration of social volatility and temporal foci as accelerators of economic meltdowns: A qualitative case study will scrutinize what socio-psychological mechanisms potentially accelerate economic meltdowns with attention to collective moods to shape the daily choices and present behavior. The role of temporal foci will be explored - whether it makes a difference if media attention focuses on the past, present or future. Country differences of novel communication techniques will elucidate varieties of digitalization around the world. 
Empirically, different communication strategies will be qualitatively analyzed. Social Representations Theory and the Core-and-Periphery Analysis content analysis based on word count but also viral online content shares will serve to categorize various approaches to introduce the external pandemic shock. Methodologically, linguistic text analyses of news reports about the societal situation and the economy aim at depicting how media representations echo in economic correlates measured by the CBOE Volatility Index retrieved online.

The qualitative exploration targets at showing economic cycles' natural complexity influenced by socio-historic trends and their media representation. Addressing the different uses of the internet and modern communication tools around the global but also understanding how temporal foci and emotional prospects can shape collective moods offers to detect concrete media strategies and communication contents that stabilize economies during external shocks.

Study 2: Temporal volatility and framing online experiment: A behavioral economics experiment will backtest the findings of the Study 1 exploration in an Amazon Mechanical Turk (AMTURK) online survey enabled via Qualtrics. A 240 subjects-strong sample from around the world tested in a controlled online survey setting will elucidate how temporal or emotional information anchors elicit affective ebbs and flows that influences choices. The role of the media in cultivating human present biases or setting an anchor of favorable and unfavorable time prospects but also using discounting theory with attention to loss aversion will be investigated. Different emotional cues will prime individuals into different affects and temporal perspectives to then decide on fictitious consumption and investment options and providing demographic information (age, gender):

(1) present bias: subjects receive 'now' present information (Test group 1),

(2) future bias: subjects receive either positive (Test group 2.1), negative (Test group 2.2) or neutral (Test group 2.3) information about the 'future,'

(3) past bias: subjects receive either positive (Test group 3.1), negative (Test group 3.2) or neutral (Test group 3.3) information about the 'past.'

(4) control group with no information making fictitious consumption and investment choices. Hypothesis 1 tests if 'now' eliciting media information increases the present bias. Hypothesis 2 clarifies if positive information triggers more consumption and investment in the domains of culture, economics, education, environment, foreign aid and infrastructure than negative information. Hypothesis 3 investigates if 'future' information triggers more consumption and investment in the domains of culture, economics, education, environment, foreign aid and infrastructure than 'past' information. Hypothesis 4 investigates if positive or negative emotions or forward-looking or past-ruminating temporal foci lead to a delay in consumption and investment in the domains of culture, economics, education, environment, foreign aid and infrastructure. Hypothesis 5 captures age dependent discounting preferences as alternative reference point.

Study 3: Country differences in social volatility and digitalization differences: A quantitative cross-sectional study will compare country differences in COVID-19 pandemic communication strategies' impact on economic performance while controlling for the lockdown strategy and infected population with the government as moderator variables. Data on online communication of the G-20 on COVID-19 will be retrieved from the Federal Reserve Banks of St. Louis and Kansas and Worldometer. Lockdown strategy categorizations will be metacategorized and the quality of the category system quantified by Cohen's Kappa as an interraterreliability test. Communication will be rated on being positive, negative, neutral based on Polarity indices and having a past, present or future-oriented outlook based on Hofstede's cultural future-oriented versus past-tradition oriented indicators. Infected population per inhabitants are retrieved from the Worldometer Coronavirus homepage. Economic performance measured by Gross Domestic Product (GDP) growth percentage changes and GDP per capita is available at the International Monetary Fund (IMF), Worldbank (WB) and Macrobond homepages. Methodologically, regressions will compare and contrast between the country clusters' pandemic communication strategies' in relation to economic correlates. Attention to 
digitalization differences is operationalized by the online-documented Global Connectivity Index and The State of the Mobile Internet Connectivity Index and the NASDAQ Yewno Global Artificial Intelligence and Big Data Index measuring international market growth in the digital domain.

Overall, communication influences on market expectations and performance shaping economic cycles will reveal information contents that either cause social volatility bleeding into economic downturns or serve as crowd control stabilizers.

Study 4: Endogenous versus exogenous shock regrowth recovery: Economic time episodes studies will compare economic fundamentals based on financial stress test indicators. Time window $t_{1}$ from 2006 to 2011 covers the 2008/09 World Financial Recession economic fallout and subsequent recovery. Similarity to time window $t_{2}$ ranging from 2017 until shortly before the COVID-19 pandemic outbreak will be calculated with Pearson's correlations for each time sequence of measurement interval. Evidence of economic fluctuations will reveal the inherently unstable character of markets. Time window $t_{3}$ will capture the period from the novel Coronavirus pandemic outbreak. Overlaying the two windows $t_{1}$ and $t_{3}$ for each time sequence of measurement interval within the windows will differentiate between capitalism-inherent crisis captured in $t_{1}$ and the currently exogenous shock recovery $t_{3}$ period recovery strategies. Differentiating between two timely-close (almost all else held equal condition) but systemicallydiffering (internal capitalism failure vs. external shock fallout) causes of economic crises will have invaluable implications for the nature of capitalism, endogenous and exogenous growth and economic cycle theories in order to retrieve strategic recovery recommendations. Attention will also be paid to contemporary digitalization trends.

As for the operationalization of Study 4, find the economic crises indicators in Table 1.

Table 1: Economic and financial crises predictions ${ }^{1}$

\begin{tabular}{|c|c|c|c|c|}
\hline Growth & Monetary policy & Commodities & Trade & Financial Soundness \\
\hline GDP & Consumer price index & Gold & Trade weighted US dollar index & Financial Soundness Indicator \\
\hline \multirow[t]{6}{*}{ Employment } & Purchasing Managers Index & Commodity & Trade in goods and services as $\%$ of GDP & Interbank Spread \\
\hline & Interest Rate & & FDI inflows as \% of GDP & Corporate Bond Yield \\
\hline & & & & 12-month rolling Beta of Bank Stock Index \\
\hline & & & & Monthly stock returns \\
\hline & & & & Inverted term spread \\
\hline & & & & Six month rolling monthly squared change in REER \\
\hline
\end{tabular}

Table 1 holds the macroeconomic financial crisis indicators to be compared in a time warp method. First, a set of crisis indicators will be retrieved online for the time windows $t_{1}$ (covering years 2006 to 2011), $t_{2}$ (years 2017-2019) and $t_{3}$ (beginning 2020 until the last data point available). A time warp based similarity index will be based on Pearson's correlations. For each time window and each time period, a correlation of the overlap between the timelines of $t_{1}$ and $t_{2}$ as well as $t_{1}$ and $t_{3}$ will be calculated. The timeline will comprise of percentage changes of the current period in relation to the previous period based on equation 1 calculus:

Percentage changes $=\left(\frac{((t+1)-t)}{t}\right) * 100$

(Equation 1)

In case of significant positive correlations, a similarity will be assumed between the time windows in the respective macroeconomic crises variable. The retrieved positively significant correlations will then be integrated into a crisis time warp overlap similarity index. All time

\footnotetext{
${ }^{1}$ Economic growth is measured in GDP, the Consumer Price Index and the Interest Rate as well as the Trade weighted US dollar index by the Federal Reserve Bank of St. Louis homepage. The Purchasing Managers Index is retrieved online. Gold and Commodity prices are found in Index Mundi. Trade in goods and services as percentage of GDP is available on the OECD homepage. Trade depicted in FDI inflows as percent of GDP is provided by the WB. The Financial Soundness Indicator, Interbank spread, Corporate Bond Yields and 12-months rolling Beta of monthly stock returns, Monthly stock returns, Inverted term spread and 6-month rolling monthly squared change in REER are found in an IMF database.
} 
periods with positively significant correlations then will became the basis for a Time Warp Similarity Index (TWSI) based on the following equation 2:

$T W S I=(1-p) *\left(1-\left(\frac{t-12}{12}\right)\right)$

whereby $p$ denotes the p-value of all significant time warp similarities based on Pearson's correlations and $t$ the time of missing data in months up until the end of the data. The means for all overlapping similarity time windows will be derived in order to avoid double counts.

\section{Discussion}

Overall, the research will acknowledge that human beings' communication and interaction results in socially constructed volatility that echoes in economic correlates. Understanding how the social compound forms economic outcomes promises to explain how market outcomes are developed in society and can be shaped by strategic communication with special attention to new media technologies.

The discussion will highlight the uniqueness and differences of the 2019 COVID pandemic economic fallout from the 2008/09 World Financial Recession. While the previous recession was inherent in the system of capitalism and largely played out in financial constraints affecting almost all industries, the novel 2019 COVID pandemic imposes an external shock that was fueled by communication and interaction, which differed throughout the world. The currently ongoing market communication about the pandemic serves as historic trace, whose conservation offers important insights about how the socio-psychological interpretation of an external shock echoes in economic fundamentals. The discussion will also target at highlighting winning and losing industries only to follow the mandate to find creative strategies how to redistribute the gains of the crisis in order to offset the economic fallout losses in proposed inequality alleviation strategies. The final remarks will also discuss the contemporary divide between economic fundamentals, financial market performance versus the real economy fallout.

Implications will stress how communication can counterweight and alleviate the building of collective moods bleeding into disastrous mass movements causing turmoil in financial market and steering economic fallouts with negative implications for societies' weakest segments. Recommendations how to build stable economic systems by avoiding emergent risks and communicating market prospects favorably may help building the fundamental architecture of future more stable markets to be crafted by heterodox economists and off-mainstream public policy experts. A prospective future research outlook and implications will be offered aimed at improving the economic future of healthcare, workforce, city planning and education based on strategic communication and emotional assets but also favorable time prospects in our postCOVID-19 world to come.

\section{References}

Centeno, Miguel Angel, Creager, A.N., Elga, A., Felton, E., Katz, St.N., Massey, W.A. \& Shapiro, J.N. 2013. Global systemic risk: Proposal for a research community. Princeton University, NJ: Princeton Institute for International and Regional Studies working paper, 2013.

CDC Center for Disease Control and Prevention, Symptoms of Coronavirus Disease, Coronavirus Disease 2019 (COVID-19), https://www.cdc.gov/coronavirus/2019-ncov/symptoms-testing/symptoms.html, last visited August 12, 2020.

International Monetary Fund. 2020. Policy Responses to COVID-19, 2020, https://www.imf.org/en/Topics/imf-andcovid19/Policy-Responses-to-COVID-19, last visited August 13, 2020.

International Monetary Fund. 2020. A crisis like no other: An uncertain recovery. World Economic Outlook Update, June 2020. 
Puaschunder, Julia Margarete. 2017a. "Nugitize me! A behavioral finance approach to minimize losses and maximize profits from heuristics and biases." International Journal of Management Excellence 10(2): 12411256.

Puaschunder, Julia Margarete. 2017b. "Nudging in the digital big data era." European Journal of Economics, Law and Politics 4(4): 18-23.

Puaschunder, Julia Margarete. 2017c. "Nudgital: Critique of Behavioral Political Economy." Archives of Business Research 5(9): 54-76.

Puaschunder, Julia Margarete. 2017d. "The nudging divide in the digital big data era." International Journal of Research in Business, Economics and Management 4(11-12): 49-53.

Puaschunder, Julia Margarete. 2019. "Revising growth theory in the artificial age: Putty and clay labor." Princeton University working paper.

Puaschunder, Julia Margarete. forthcoming. "Towards a utility theory of privacy and information sharing and the introduction of hyper-hyperbolic discounting in the digital big data age." Encyclopedia of Information Science and Technology.

Puaschunder, Julia Margarete \& Dirk Beerbaum. 2020. "Healthcare inequality in the digital $21^{\text {st }}$ century: The case for a mandate for equal access to quality medicine for all." Book of abstract of the Unequal World Conference. United Nations New York, New York, United States.

Puaschunder, Julia Margarete, Martin Gelter \& Siegfried Sharma. 2020. „COVID-19-Shock: Socio-Technological, Legal, Corporate, Economic and Governance Changes." Proceedings of the 18th Interdisciplinary Research Association for Interdisciplinary Studies (RAIS) conference, August 17-18, 2020. [Held online due to COVID-19].

Sachs, Jeffrey D., Richard Horton, Jessamy Bagenal, Yanis Ben Amor, Ozge Karadag Caman \& Guillaume Lafortun. 2020. "The Lancet COVID-19 Commission." The https://www.thelancet.com/pdfs/journals/lancet/PIIS0140-6736(20)31494-X.pdf, July 9, 2020.

United Nations, 2020. UN Response to COVID-19, https://www.un.org/en/coronavirus/UN-response, last visited August 12, 2020.

United Nations Conference on Trade and Development Committee for the Coordination of Statistical Activities, 2020, How COVID-19 is changing the world: A statistical perspective, https://unstats.un.org/unsd/ccsa/documents/covid19-report-ccsa.pdf, last visited August 13, 2020. 